\title{
Solubility of Flurbiprofen in Supercritical Carbon Dioxide
}

\author{
Ana Rita C. Duarte, ${ }^{\dagger}$ Patrícia Coimbra, ${ }^{\ddagger}$ Hermínio C. de Sousa, ${ }^{\ddagger}$ and Catarina M. M. Duarte*,†
}

Instituto de Biologia Experimental e Tecnológica, Aptd. 12-2780 Oeiras, Portugal, and Dep. de Engenharia Química, FCT, Universidade de Coimbra, Pólo II-Pinhal de Marrocos, 3030-290 Coimbra, Portugal

Equilibrium solubility of flurbiprofen, a nonsteroidal antiinflammatory agent, in supercritical carbon dioxide was measured by a static analytical method in the pressure range from (8.0 to 25.0) $\mathrm{MPa}$, at temperatures of (303.0, 313.0, and 323.0) K. The cosol vent effect of ethanol in the solubility of the bioactive compound in supercritical carbon dioxide was investigated at $18 \mathrm{MPa}$ and $313 \mathrm{~K}$. The results obtained have a potential application in supercritical processes for this drug. Experimental solubility data were correlated with an empirical density-based Chrastil model.

\section{Introduction}

This work is part of a research project designed for the development of polymeric controlled drug release systems (CDRS) for ophthalmic applications, namely, for glaucoma and several other corneal pathologies treatment, using "clean and environmental friendly" supercritical processes.

In products for medical and pharmaceutical applications, the presence of residual organic solvents is rigorously controlled by international safety regulations. Thus, it is necessary to warrant the complete removal and absence of these substances, without exposing the polymers and drugs contained in a typical polymeric CDRS to high temperatures that could degrade them. In this sense, supercritical fluids (SCFs) can be very attractive solvents. Supercritical carbon dioxide $\left(\mathrm{T}_{\mathrm{C}}=31^{\circ} \mathrm{C}\right.$ and $\mathrm{P}_{\mathrm{C}}=73$ bar), due to its relatively low critical temperature, is less likely to degrade thermally labile substances. SC carbon dioxide has other important advantages, including the fact that it is nontoxic, nonflammable, and inexpensive. Some CDRSs and other medical applications have been developed using techniques involving SC $\mathrm{CO}_{2} \cdot{ }^{1-8}$ The design of chemical and pharmaceutical processes based on SCFs and the determination of their best operating conditions requires a knowledge of phase equilibria and drug solubility in a supercritical fluid. In the last two decades, solubility in SCFs of a large number of different low-volatility compounds have been measured, reported, and reviewed..$^{9-16}$ However, the development of new supercritical processes and new applications for existing substances has maintained the need for new experimental solubility determinations.

For organic compounds having high molecular masses, supercritical solubility is usually low. Thus high temperatures and pressures are required for substantial solid loadings in a supercritical phase. For example, although carbon dioxide is the most common SCF used by industry, it does have limitations due to its lack of polarity and its associated deficiency of specific solvent-solute interactions which would lead to high loading and/or selectivity for polar organic compounds. To improve polarity/selectivity, it was

\footnotetext{
* To whom correspondence should be addressed. E-mail: cduarte@ itqb.unl.pt. Fax: +351 214421161.

t Instituto de Biologia Experimental e Tecnológica.

₹ Universidade de Coimbra.
}

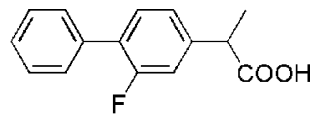

Flurbiprofen

$$
\mathrm{MW}=244.3 \mathrm{~g} / \mathrm{mol}
$$$$
\text { m.p. }=110-112^{\circ} \mathrm{C}
$$

Figure 1. Chemical structure of flurbiprofen, CAS [5104-49-4], 2-fluoro-al pha-methyl-4-biphenylacetic acid.

found that the addition of small amounts of a so-called cosolvent or entrainer (usually a polar substance) to a SCF can produce dramatic effects on its solvent power, sometimes up to several hundred percent of solubility enhancement. ${ }^{17,18}$ The entrainer can be a gas, a liquid, or a supercritical fluid. ${ }^{19}$

Flurbiprofen (Figure 1) is a well-known chiral nonsteroidal antiinflammatory agent with analgesic and antipyretic activity. It is one of the most potent inhibitors of platelet aggregation, and it is used to treat gout, osteoarthritis, rheumatoid arthritis, and sunburn. In ophthalmic applications, it is used to prevent pupil constriction and to reduce pain and inflammation in the eye. Because it does not influence intraocular pressure, it can be prescribed to patients suffering from glaucoma. ${ }^{20,21}$

In this work, the equilibrium solubility of flurbiprofen in supercritical carbon dioxide was measured from (8.0 to 25.0) $\mathrm{MPa}$ at $(303.0,313.0$, and 323.0) $\mathrm{K}$. The effect of adding ethanol as a cosolvent in the solubility of the bioactive compound in supercritical carbon dioxide was investigated at $18.0 \mathrm{MPa}$ and $313.0 \mathrm{~K}$. The static analytical apparatus used for solubility measurements is briefly described and the experimental procedure presented. Solubility data results were correlated applying the Chrastil's empirical density-based model.

\section{Experimental Section}

Materials. Flurbiprofen, CAS [5104-49-4] (97\% purity) was purchased from Sigma-Aldrich. Dichloromethane, CAS [75-09-2] (99.95\% purity), was purchased from Fluka. Ethanol, CAS [64-17-5] (99.8\% purity), was purchased from Riedel-de Häen. Carbon dioxide (99.998 mol \%) was supplied by Air Liquide. All chemicals were used without any further purification. 


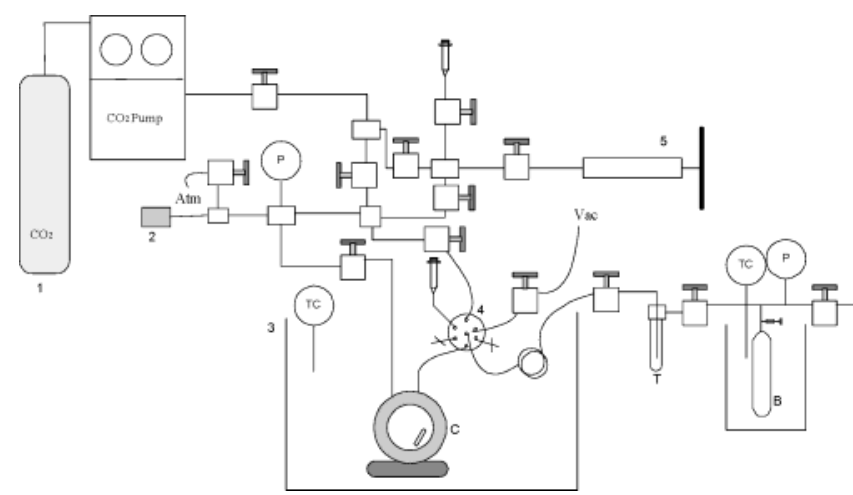

Figure 2. High-pressure apparatus for solubility measurements: $1, \mathrm{CO}_{2}$ compressor; 2 , rupture disk; 3, thermostatic water bath; 4, six port-sampling HPLC valve; 5, manual syringe; $\mathrm{P}$, pressure transducer; TC, temperature controller; $\mathrm{C}$, equilibrium cell with sapphire windows; T, glass trap; B, expansion-calibrated cylinder.

Experimental Procedures. The solubility of flurbiprofen was measured using a static analytic high-pressure apparatus, schematically presented in Figure 2. The determination of the solubility was performed in a similar manner to that described by $M$ atias et al. ${ }^{22} \mathrm{~A}$ stainless steel equilibrium visual cell, with an internal volume of approximately $30 \mathrm{~cm}^{3}$, is immersed in a thermostatic water bath, heated by means of a controller that maintained temperature within $\pm 0.1{ }^{\circ} \mathrm{C}$. The cell is initially loaded with the solid and a magnetic internal stirrer. Carbon dioxide is pumped into the cell using a pneumatic compressor until the desired pressure is attained. The pressure inside the cell is measured with a pressure transducer (SETRA, model 204, (0 to $34.40 \pm 0.04$ ) MPa), calibrated between 0 and $20.6 \mathrm{MPa}$.

The mixture of $\mathrm{CO}_{2}+$ flurbiprofen is stirred for $1 \mathrm{~h}$, a typical equilibration time. After $30 \mathrm{~min}$ of rest for equilibration, samples from the gas (top) phase are taken through a six-port sampling HPLC valve. These samples are collected by a quick depressurization and expansion into a small glass trap. The gas in the samples is expanded into calibrated volumes, and the amount of $\mathrm{CO}_{2}$ in each sample is calculated from the measurement of the resulting subatmospheric pressure increase at the working temperature.

Pressure, after the expansion, is measured with a pressure transducer (SETRA, model 204, (0 to $0.17 \pm 1.9$ $\times 10^{-4}$ ) $\mathrm{MPa}$ ). To ensure that all solute is recovered in the trap, ethanol is injected through the sample loops and expansion lines. Finally, the lines are cleaned with fresh carbon dioxide smoothly pressurized.

For the experiments with cosolvent, to ensure that the molar fraction of ethanol was kept constant, some changes were made in the experimental apparatus. A manual syringe pump (HIP, model 87-6-5) was coupled to the system and was kept under constant temperature with circulating water coming from a thermostatic bath. In all these experiments, the cell was pressurized with the mixture of ethanol and carbon dioxide inside this syringe pump.

Analytical Method. The collected samples were diluted in ethanol to a convenient volume. To determine the amount of flurbiprofen, the resulting solutions were analyzed by UV spectrophotometry in a UV-vis (Cary 3EVarian). Flurbiprofen absorbs in the region of ultraviolet, with a maximum absorbance at $247 \mathrm{~nm}$. Calibration was obtained by using of standard samples with concentrations between $\left(1.0 \times 10^{-5}\right.$ and $\left.2.0 \times 10^{-4}\right) \mathrm{M}$.

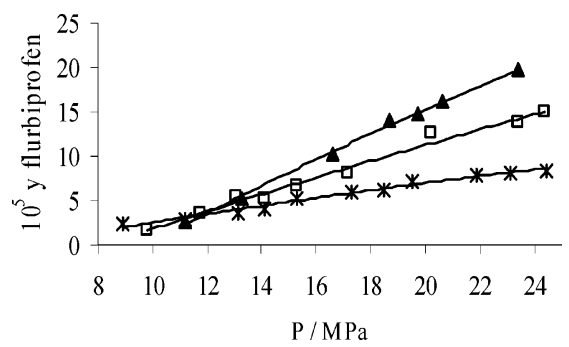

Figure 3. Solubility isotherms of flurbiprofen in supercritical carbon dioxide as a function of pressure: *, 303.0 K; $\square, 313.0 \mathrm{~K}$; $\Delta, 323.0 \mathrm{~K}$. Lines represent a polynomial fit to the experimental data points.

Table 1. Solubilities of Flurbiprofen in Supercritical Carbon Dioxide

\begin{tabular}{|c|c|c|c|c|}
\hline $\mathrm{T} / \mathrm{K}$ & $\mathrm{P} / \mathrm{MPa}$ & $\rho \mathrm{CO}_{2} / \mathrm{g} \mathrm{L}^{-1} 26$ & Yflurbiprofen $\left(10^{5}\right)$ & solubility in $\mathrm{CO}_{2} / \mathrm{g} \mathrm{L}^{-1}$ \\
\hline \multirow[t]{11}{*}{303} & 8.9 & 747.7 & 2.17 & 0.10 \\
\hline & 11.2 & 791.4 & 2.897 & 0.13 \\
\hline & 13.1 & 821.7 & 3.530 & 0.16 \\
\hline & 14.1 & 834.7 & 4.144 & 0.19 \\
\hline & 15.3 & 847.6 & 5.312 & 0.25 \\
\hline & 17.3 & 867.4 & 5.991 & 0.28 \\
\hline & 18.5 & 878.7 & 6.236 & 0.30 \\
\hline & 19.5 & 887.1 & 7.259 & 0.36 \\
\hline & 21.9 & 906.0 & 7.896 & 0.40 \\
\hline & 23.1 & 913.5 & 8.211 & 0.42 \\
\hline & 24.5 & 921.4 & 8.337 & 0.43 \\
\hline \multirow[t]{9}{*}{313} & 9.8 & 616.9 & 1.672 & 0.06 \\
\hline & 11.8 & 714.0 & 3.608 & 0.14 \\
\hline & 13.1 & 746.1 & 5.389 & 0.22 \\
\hline & 14.1 & 767.7 & 5.250 & 0.22 \\
\hline & 15.3 & 786.3 & 6.646 & 0.29 \\
\hline & 17.1 & 811.7 & 8.116 & 0.37 \\
\hline & 20.2 & 807.2 & 12.563 & 0.52 \\
\hline & 23.4 & 841.7 & 13.904 & 0.55 \\
\hline & 24.4 & 876.6 & 14.950 & 0.73 \\
\hline \multirow[t]{7}{*}{323} & 11.2 & 534.0 & 2.603 & 0.08 \\
\hline & 13.3 & 654.6 & 5.272 & 0.19 \\
\hline & 16.6 & 736.1 & 10.179 & 0.42 \\
\hline & 17.7 & 767.1 & 14.012 & 0.60 \\
\hline & 19.7 & 784.0 & 14.838 & 0.65 \\
\hline & 20.6 & 792.0 & 16.213 & 0.71 \\
\hline & 23.4 & 823.6 & 19.683 & 0.90 \\
\hline
\end{tabular}

\section{Results and Discussion}

In this work, the solubility of flurbiprofen in carbon dioxide was determined at $303.0 \mathrm{~K}, 313.0 \mathrm{~K}$, and $323.0 \mathrm{~K}$, from (8.0 to 25.0) MPa. In Table 1 and Figure 3, the solubility of flurbiprofen is expressed in terms of flurbiprofen mole fraction ( $\left.\mathrm{y}_{\text {flurbiprofen }}\right)$ and in terms of mass of solute per unity of volume of supercritical $\mathrm{CO}_{2}$. Each data point is the average of, at least, two measurements with an average absolute relative deviation, AARD, of 9

$$
\operatorname{AARD}(\%)=\frac{100}{n} \sum_{1}^{n} \frac{\left|S_{\text {calc }}-S_{\text {exp }}\right|}{S_{\text {exp }}}
$$

where $\mathrm{S}_{\text {exp }}$ and $\mathrm{S}_{\text {calc }}$ are the experimental and calculated solubilities for $\mathrm{n}$ data points.

At the three studied temperatures, the effect of pressure on the solute solubility follows the expected trend. The solvent capacity increases with pressure at constant temperature. This can be easily explained in simple physical terms. Density rises with increasing pressure, which means that the intermolecular mean distance of the molecules decreases and consequently the specific interaction between the solute and the solvent molecules increases, leading to higher solubility. Temperature is also an important but more complex factor affecting solubility results. It also 


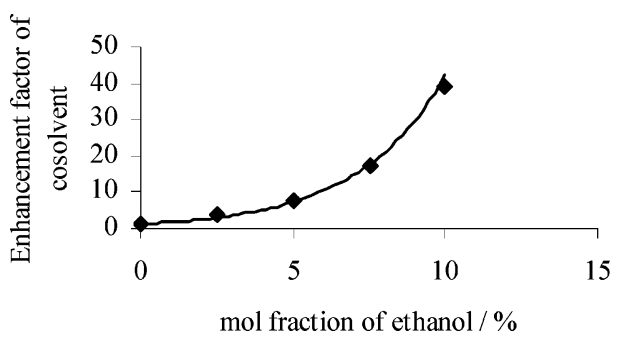

Figure 4. Enhancement factor of cosolvent at $18.0 \mathrm{MPa}$ and 313.0 $\mathrm{K}$ as a function of ethanol molar fraction. The line represents the exponential fit to the data points.

\begin{tabular}{|c|c|c|c|}
\hline $\begin{array}{c}\% \\
\text { cosolvent }\end{array}$ & $\begin{array}{l}\text { Yflurbiprofen } \\
\left(10^{4}\right)\end{array}$ & $\begin{array}{l}\text { solubility in } \\
\mathrm{CO}_{2} / \mathrm{g} \mathrm{L}^{-1}\end{array}$ & $\begin{array}{c}\text { enhancement factor } \\
\text { of cosolvent }\end{array}$ \\
\hline $\begin{array}{l}0 \\
2.5 \\
5 \\
7.5 \\
10\end{array}$ & $\begin{array}{r}0.4848 \\
3.7648 \\
7.8519 \\
15.5522 \\
36.7575\end{array}$ & $\begin{array}{r}0.427 \\
1.713 \\
3.571 \\
7.088 \\
16.776\end{array}$ & $\begin{array}{r}1 \\
4 \\
8 \\
17 \\
39\end{array}$ \\
\hline
\end{tabular}

influences solute vapor pressure, solvent density, and intermolecular interactions in the fluid phase. Figure 3 shows that the observed solubility values were higher with decreasing temperatures until a crossover region was reached, near $12.0 \mathrm{MPa}$, where the three isotherms seem to intercept and cross over each other. The decrease in SC $\mathrm{CO}_{2}$ density with increasing temperature prevails, at lower pressures, resulting in a decrease of the SCF solvent power and solubility. Above this crossover region, the effect of the temperature on solute vapor pressure overlays the effect on solvent density and solubility increases with increasing temperature.

Ethanol is one of the few organic solvents considered suitable for contact with products for human consumption, at moderate concentrations. Ethanol cosolvent's effect in flurbi profen's solubility in $\mathrm{SC} \mathrm{CO}_{2}$ was studied at $18.0 \mathrm{MPa}$ and $313.0 \mathrm{~K}$. Four different ethanol concentrations, 2.5, 5.0, 7.5 , and $10.0 \mathrm{~mol} \%$, were investigated. The results obtained are indicated in Table 2 and illustrated in Figure 4 , where the solubility enhancement of flurbiprofen in the supercritical phase is plotted as a function of the ethanol concentration. The enhancement factor of cosolvent corresponds to the ratio between the solubility of flurbiprofen in the presence of ethanol and the solubility in pure carbon dioxide, and it follows an exponential trend.

Correlation of Experimental Solubility Data. Having experimental solubility data in SCF solvents, it is also useful to devel op theoretical models to correlate and predict solid-fluid equilibrium, which afterward can be used to optimize SCF processes. Usually the SCF is treated as a compressed gas, and pressure and/or density are chosen as the independent variables. Thus, equations of state (EOS) and, undoubtedly, simple cubic EOS, together with different mixing and combining rules, are the most widely used models to correlate and predict solid-SCF equilibrium. ${ }^{17}$ However, even simple and more general cubic EOS normally require critical parameters and acentric factors for solvent and solutes that are frequently unavailable in the literature, especially for pharmaceutical compounds, polymers, biomolecules, and other less common substances. Other difficult to obtain thermophysical data include intermolecular energy parameters, boiling points, melting points, solid molar volumes, sublimation and vaporization enthal pies, and vapor-pressure curves. Moreover, the available estimation methods found in the literature for such

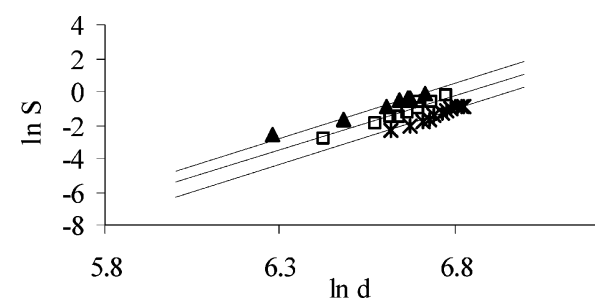

Figure 5. Logarithmic relationship between solubility of flurbiprofen and the density of supercritical $\mathrm{CO}_{2}$ at *, 303.0 K; $\square, 313.0$ $\mathrm{K} ; \boldsymbol{\Delta}, 323.0 \mathrm{~K}$. Lines represent Chrastil's regression fit.

complex molecules are mostly empirical and often lead to inconsistent and unreliable results. ${ }^{16,23}$ Another disadvantage is that most models require one or more temperaturedependent interaction parameters which must be correlated from experimental solubility data. More complicated EOS models (e.g., SAFT) and mixing rules (e.g., WongSandler) were developed but still need more adjustable parameters. ${ }^{24}$

To avoid some of these disadvantages as well as more complicated computational routines, most authors opt to use more simple empirical correlations such as densitybased equations. These empirical models are based on simple error minimization using least-squares methods, and for the majority of them, there is no need to estimate and use thermophysical properties. The most commonly used model is Chrastil's model, 25 which correlates the solubility of a solute, in a supercritical solvent, to the density and temperature. This model is based on the hypothesis that each molecule of a solute associates with $\mathrm{k}$ molecules of supercritical solvent, to form a solvato complex, which is in equilibrium with the system. The Chrastil's relationship between solubility and density can be expressed as

$$
\mathrm{S}=\rho^{\mathrm{k}} \exp (\mathrm{a} / \mathrm{T}+\mathrm{b})
$$

where $\mathrm{S}$ is the solubility $\left(\mathrm{g} \mathrm{L}^{-1}\right)$ of flurbiprofen in $\mathrm{SC} \mathrm{CO}_{2}$, $\rho$ is the density $\left(\mathrm{g} \mathrm{L}^{-1}\right)$ of the pure $\mathrm{CO}_{2}$ at the experimental absol ute temperature (K), T, and pressure, $p$. The constant, k, expresses an average equilibrium association number, which is a characteristic constant for a given gas-solute system. The parameter a is defined as $\Delta \mathrm{H} / \mathrm{R}$, where $\Delta \mathrm{H}$ is the sum of the enthalpies of vaporization and solvation. Finally, the parameter $b$ is dependent on the molecular weights of solvent and solute.

Correlation and prediction of the solubility of flurbi profen in supercritical $\mathrm{CO}_{2}$ is very important for the application of supercritical fluid technology in processing this bi oactive compound. In this work, the experimental solubility data for flurbiprofen were correlated using the previously described semiempirical Chrastil method. The logarithmic solubility-density relationship shows a linear behavior for all the isotherms, as it is illustrated in Figure 5. By performing a multiple linear regression on $\operatorname{In} S$ as a function of $\ln \rho$ and $1 / T$, one obtains $\mathrm{k}=6.5( \pm 0.2)$, $\mathrm{a}=$ $-7582( \pm 232)$, and $b=-20.3( \pm 0.8)$. The thermodynamic quantity, $\Delta \mathrm{H}$, can be calculated directly from a, resulting, for the studied system, in a value of $-62.98 \mathrm{~kJ} \mathrm{~mol}^{-1}$. The average absolute relative deviation of the fitted Chrastil equation from experimental data was calculated to be $10 \%$.

\section{Conclusions}

Equilibrium sol ubility of flurbiprofen in supercritical $\mathrm{CO}_{2}$ was measured by a static analytical method, in the pressure range from (8.0 to 25.0) $\mathrm{MPa}$ at (303.0, 313.0, and 323.0) K. Equilibrium solubility data, expressed in terms 
of flurbi profen's mole fraction, ranges from (1 to 20$) \times 10^{-5}$, with an AARD of $9 \%$. At a constant temperature, the solvent capacity increases with increasing pressure. Near 12.0 MPa, the three isotherms intercept, which reveals the approach of a crossover region. Below this pressure value, solubility increases with decreasing temperature, and above 12.0 MPa, the effect of the temperature on the solute vapor pressure overlays the effect on the solvent density, resulting in an increase of the solubility with the temperature increase.

The ethanol cosolvent effect on flurbiprofen's solubility in supercritical $\mathrm{CO}_{2}$ was studied at $18.0 \mathrm{MPa}$ and 313.0 K. F our different ethanol concentrations $(2.5,5.0,7.5$, and 10.0) $\mathrm{mol} \%$ were investigated. The solubility of flurbiprofen in supercritical $\mathrm{CO}_{2}+$ ethanol follows an exponential trend.

Application of Chrastil's density-based model to the experimental data leads to values of $\mathrm{k}=6.5( \pm 0.2), \mathrm{a}=$ $-7582( \pm 232), \mathrm{b}=-20.3( \pm 0.8)$, and $\Delta \mathrm{H}=-62.98 \mathrm{~kJ}$ $\mathrm{mol}^{-1}$. These data were correlated with a maximum AARD of $10 \%$.

The solubility results obtained in this work are very promising for the development of supercritical processes for pharmaceutical applications based on this drug.

\section{Literature Cited}

(1) Kikic, I.; Sist, P. Applications of Supercritical Fluids to Pharmaceuticals: Controlled Drug Release Systems. In Supercritical Fluids: Fundamentals and Applications, Proceedings of the 2 nd NATO ASI on Supercritical Fluids, NATO Science Series; Kiran, E., Debenedetti, P. G., Peters, C. J ., Eds.; Kluwer: Dordrecht, The Netherlands, 2000; pp 291-306.

(2) Kirby, C. F.; McHugh, M. A. Phase Behavior of Polymers in Supercritical Fluid Solvents. Chem. Rev. 1999, 99, 565-602.

(3) Kompella, U. B.; Koushik, K. Preparation of Drug Delivery Systems Using Supercritical Fluid Technology. Crit. Rev. Ther. Drug Carrier Syst. 2001, 18, 173-199.

(4) Kazarian, S. G. Polymer Processing with Supercritical Fluids. Polym. Sci., Ser. C 2000, 42, 78-101.

(5) Knez, Z.; Weidner, E. Precipitation of Solids with Dense Gases. In High-Pressure Process Technology: Fundamentals and Applications; Bertucco, A., Vetter, G., Eds.; Elsevier Science: Amsterdam, The Netherlands, 2001; pp 587-611.

(6) Elvassore, N.; Kikic, I. Pharmaceutical Processing with Supercritical Fluids. In High-Pressure Process Technol ogy: Fundamentals and Applications; Bertucco, A., Vetter, G., Eds.; Elsevier Science: Amsterdam, The Netherlands, 2001; pp 612-625.

(7) J ung, J ;; Perrut, M. Particle Design Using Supercritical Fluids: Literature and Patent Survey. J . Supercrit. Fluids 2001, 20, 179219.

(8) Webb, P. B.; Marr, P. C.; Parsons, A. J .; Gidda, H. S.; Howdle, S. M. Dissolving Biomolecules and Modifying Biomedical I mplants with Supercritical Carbon Dioxide. Pure Appl. Chem. 2000, 72, 1347-1355.
(9) Kurnik, R. T.; Holla, S. J .; Reid, R. C. Solubility of Solids in Supercritical Carbon Dioxide and Ethylene. J. Chem. Eng. Data 1981, 26, 47-51.

(10) Fornari, R. E.; Alessi, P.; Kikic, I. High-Pressure Fluid Phase Equilibria: Experimental Methods and System Investigated (1978-1987). Fluid Phase Equilib. 1990, 57, 1-33.

(11) Bartle, K. D.; Clifford, A. A.; J afar, S. A. Solubilities of Solids and Liquids of Low Volatility in Supercritical Carbon Dioxide. J . Phys. Chem. Ref. Data 1991, 20, 713-757.

(12) Dohrn, R.; Brunner, G. High-Pressure Fluid Phase Equilibria: Experimental Methods and System Investigated (1988-1993). Fluid Phase Equilib. 1995, 106, 213-282.

(13) Macnaughton, S. J .; Kikic, I.; Foster, N. R.; Alessi, P.; Cortesi, A.; Colombo, I. Solubility of Antiinflammatory Drugs in Supercritical Carbon Dioxide. J . Chem. Eng. Data 1996, 41, 1083-1086.

(14) Santiago, J . M.; Teja, A. S. The Solubility of Solids in Supercritical Fluids. Fluid Phase Equilib. 1999, 158-160, 501-510.

(15) Lucien, F. P.; Foster, N. R. Solubilities of Solid Mixtures in Supercritical Carbon Dioxide: A Review. J. Supercrit. Fluids 2000, 17, 111-114.

(16) J ouyban, A.; Chan, H.-K.; Foster, N. R. Mathematical Representation of Solute Solubility in Supercritical Carbon Dioxide Using Empirical Expressions. J. Supercrit. Fluids 2002, 24, 19-35.

(17) Brunner, G. Selectivity of Supercritical Compounds and Entrain ers with Respect to Model Substances. Fluid PhaseEquilib. 1983, 10, 289-298.

(18) Eckert, C. A.; Knutson, B. L.; Debenedetti P. G. Supercritical Fluids as Solvents for Chemical and Materials Processing. Nature 1996, 383, 313-318.

(19) Schmitt, W. J .; Reid, R. C. The Use of Entrainers in Modifying the Solubility of Phenanthrene and Benzoic Acid in Supercritical Carbon Dioxide and Ethane. Fluid Phase Equlib. 1986, 32, 7799.

(20) Fang, J .-Y.; Hwang, T.-L.; Leu, Y.-L. Effect of Enhancers on Percutaneous Absorption of Flurbiprofen from Hydrogels. Int. J . Pharm. 2003, 250, 313-325.

(21) Gieser, D. K.; Hodapp, E.; Kass, M. A. Flurbiprofen and Intraocular Pressure. Ann. Ophthalmol. Glaucoma 1981, 13, 831-833.

(22) Matias A. A.; Nunes A. V. M.; Casimiro T.; Duarte C. M. M. Solubility of Coenzyme Q10 in Supercritical Carbon Dioxide. J . Supercrit. Fluids 2004, 28, 201-206

(23) Garnier, S.; Neau, E.; Alessi, P.: Cortesi, A : Kikic, I. Modeling Solubility of Solids in Supercritical Fluids Using Fusion Properties. Fluid Phase Equilib. 1999, 158-160, 491-500.

(24) Xu, G.; Scurto, A. M.; Castier, M.; Brennecke, J. F.; Stadtherr M. A. Reliable Computation of High-Pressure Solid-Fluid Equilibrium. Ind. Eng. Chem. Res. 2000, 39, 1624-1636.

(25) Chrastil, I. Solubility of Solids in Supercritical Gases. J . Phys. Chem. 1982, 86, 3016-3021.

(26) Thermodynamic Properties of Fluids. Program from the "Center of Applied thermodynamic Studies College of Engineering, University of Idaho, Moscow, Idaho, 1991".

Received for review May 30, 2003. Accepted February 13, 2004. Ana Rita C. Duarte is grateful for financial support from a SFRH/BD/ 10780/2002 grant. This work was financially supported by FCTMCES and FEDER, Portugal, under Contract POCTI/FCB/38213/ 2001.

J E034099B 